\title{
Uncertainty analysis of the kinetic model of natural gas combustion in IC Engine
}

\author{
Mansha M. ${ }^{*}$, Javed H Naqvi ${ }^{1}$ \\ ${ }^{1}$ Department of Chemical Engineering, University of Engineering \& Technology Lahore, Pakistan \\ "Corresponding author: e-mail: muhammad_mansha@uet.edu.pk
}

\begin{abstract}
The purpose of this analysis is to determine the uncertainties originating due to the kinetic parameters of the rate of a reaction proposed kinetic model. A kinetic model consisting of 208 reaction steps and 73 species was adopted for analysis. In the required uncertainty analysis, the accuracy of approximate models, generated by the Chemkin 4.1.1 for pollutant species, is determined. The reactions which contribute the uncertainty in the output concentrations of the pollutnats species formed in the combustion chamber were identified. The percentage contribution to the uncertainty in the output concentrations of pollutants were also determined.
\end{abstract}

Keywords: Kinetics model, uncertainty analysis, error analysis, pollutants.

\section{INTRODUCTION}

Combustion is a very complex phenomenon, characterized by interaction and competition of various physical and chemical processes. The correct description of chemical changes requires the application of reaction mechanisms consisting of several hundred or thousand reactions. This means that the chemistry of combustion processes is described by a huge number of parameters and hence the application of sensitivity analysis techniques is very useful for its understanding. Applications of sensitivity methods in chemical kinetics have been reviewed several times. Rabitz et al. concentrated mainly on the interpretation of sensitivity coefficients in reaction-diffusion systems ${ }^{1}$.

Turinyi considered sensitivity methods as tools for studying reaction kinetics problems ${ }^{2}$. This review contains an almost complete list of publications on the application of sensitivity analysis in reaction kinetics up to 1989. Recently, Radhakrishnan has published several articles $^{3-4}$ on the numerical comparison of methods for the calculation of local sensitivities. Tomlin et al have discussed sensitivity analysis as one of the mathematical tools applied in combustion chemistry ${ }^{5}$.

There is a wide application of detailed kinetic reaction mechanisms in multiple fields of application such as atmospheric chemistry, combustions systems, pyrolysis etc. These proposed reaction models have been verified or tested against experimental measurements. Usually, both experimental results and simulation based results do not coincide perfectly. The level of agreements between the results can be estimated by measurements errors and uncertainty existing in the simulation results.

The uncertainty factor due to Factor "A" of Arrhenius Rate Law is defined as;

$f_{j}=\log _{10}\left(\frac{k_{j}^{\circ}}{k_{j}^{\text {min }}}\right)=\log _{10}\left(\frac{k_{j}^{\text {max }}}{k_{j}^{\circ}}\right)$

Where $k_{j}{ }^{0}$ is the recommended values of the rate coefficient of reaction $j$.

$k j^{\min }, k j^{\max }$ are the lower and upper limits of rate coefficients. These minimum and maximum values of rate parameters corresponding to $2^{\sigma}$ deviation from the recommended value on log scale, the uncertainty factor defined above can be converted to the variance of logarithm of rate coefficient using the relation $\sigma^{2}\left(\ln k_{j}\right)=\left(\left(f_{j} \ln 10\right) / 2\right)^{2}$. Owing to the lack of detailed information and based on central limits thermo, normal distribution was assumed for the parameter lnk. Also assuming that the reaction rate coefficients are not correlated, the variance of model output $Y_{i}$ is calculated by;

$\sigma_{k_{j}}^{2}\left(Y_{i}\right)=\left(\frac{\partial Y_{i}}{\partial \ln k_{j}}\right)^{2} \sigma^{2}\left(\ln k_{j}\right)$

$S \%_{i j}=\frac{\sigma_{j}{ }^{2}\left(Y_{i}\right)}{\sigma^{2}\left(Y_{i}\right)} \times 100$

Where, the subscript $\mathrm{K}$ means an uncertainty originating form the kinetic parameters. $\sigma^{2}\left(\operatorname{lnk}_{\mathrm{j}}\right)$

The percentage contribution of error due to each reaction involved in the formation and consumption of pollutants is defined by the equation;

$S \%_{i j}=\frac{\sigma_{j}{ }^{2}\left(Y_{i}\right)}{\sigma^{2}\left(Y_{i}\right)} \times 100$

In this equation, $\sigma_{j}{ }_{j}^{2}\left(Y_{i}\right)$ and $\sigma^{2}\left(Y_{i}\right)$ are defined further as;

$$
\begin{aligned}
& \sigma^{2}\left(Y_{i}\right)=\sigma_{k i}{ }^{2}\left(Y_{i}\right) \\
& \text { and } \\
& \sigma_{j}^{2}\left(Y_{i}\right)=\sum_{j} \sigma_{j}{ }^{2}\left(Y_{i}\right)
\end{aligned}
$$

$\sigma_{k}$, is the variance coefficients due to Factor "A" which is the temperature coefficient of respectively.

In the current study, the local uncertainty of kinetic parameters of four proposed kinetic reaction mechanism has been investigated. The contribution of errors of individual elementary reaction of a reaction mechanism was calculated by the variance analysis of the estimated models for each species. In this analysis, for each reaction, the percentage contribution of error in the predicted profile of each pollutants species is calculated under various simulation conditions.

\section{MATERIALS AND METHODS}

\section{Construction of Kinetic Reaction Mechanism}

The reaction mechanism generated by the EXGAS computer code is composed of the following three 
components ${ }^{\mathbf{6}}$;

(a) $\mathrm{C} 0-\mathrm{C} 1-\mathrm{C} 2$ reaction base

(b) The system generated primary reaction mechanism in which the species in the initial gas mixture are taken as the reactants.

(c) The secondary mechanism which contains reactions whose reactants are the molecular products of the primary mechanism.

The kinetic model is generated by following the guidelines given in Table 1 and the kinetic model developed to simulate the combustion of natural gas in IC engine in given in Table 1 . The uncertainty analysis of the kinetic model was carried out using the simulation code of Chemkin 4.1.1. The sequential calculations with kinetic parameters (Factor A of Arrhenius Rate Law) for local sensitivity coefficients were made by modifying this code. These local sensitivities were converted to uncertainty using KINALC of Chemkin 4.1.1.

Table 1. Menu followed for generation of primary mechanism by EXGAS

\begin{tabular}{|l|c|c|}
\hline \multirow{2}{*}{ Primary Reactions In EXGAS } & \multicolumn{2}{|c|}{$\begin{array}{c}\text { Options chosen for primary } \\
\text { mechanism generation and } \\
\text { simplification }\end{array}$} \\
\cline { 2 - 3 } & Yes/No & $\begin{array}{c}\text { No. of } \\
\text { Reactions }\end{array}$ \\
\hline Unimolecular initiations & Yes & 3 \\
\hline Bimolecular initiations & Yes & 3 \\
\hline Additions with oxygen & No & 0 \\
\hline Isomerizations & No & 0 \\
\hline Beta-scissions & Yes & 7 \\
\hline Decompositions to o-rings & No & 0 \\
\hline Oxidations & Yes & 3 \\
\hline Branching & No & 0 \\
\hline Metatheses & Yes & 43 \\
\hline Combinations & Yes & 10 \\
\hline Dismutations & No & 0 \\
\hline $\begin{array}{l}\text { Total Number of Reactions } \\
\text { (including base reaction) }\end{array}$ & \multicolumn{2}{|c|}{433} \\
\hline $\begin{array}{l}\text { Total Number of Primary } \\
\text { Reactions in Mechanism } \\
\text { Generated by EXGAS }\end{array}$ & \multicolumn{2}{|c|}{502} \\
\hline $\begin{array}{l}\text { Number of Reactions in } \\
\text { Lumped Primary Mechanism }\end{array}$ & \multicolumn{2}{|c|}{23} \\
\hline $\begin{array}{l}\text { Total No of reactions (After } \\
\text { Coupling with Leed's NO } \\
\text { Mechanism) }\end{array}$ & \multicolumn{2}{|c|}{60} \\
\hline No of Species & \multicolumn{2}{|c|}{208} \\
\hline No. of primary molecules & \multicolumn{2}{|c|}{} \\
\hline Number of free radicals & \multicolumn{2}{|c|}{} \\
\hline Number of lumped molecules & \multicolumn{2}{|c|}{} \\
\hline
\end{tabular}

In the present study, the reactions contributed to the formation and consumption of pollutant species (NO, $\mathrm{NO}_{2}, \mathrm{NH}_{3}$ and $\mathrm{CO}$ ) to the concentrations in the combustion chamber of IC engine with the specifications given in Table 2. The uncertainty analysis of the proposed reactions kinetic model (Adopted from Table 3 of Ref. 7) was carried out for fuel lean conditions and fuel rich conditions but the results shown in the plots were obtained at stoichiometric condition (when fuel-to-air ratio, $\varphi=1.0$ ) and when the engine was operating at $3000 \mathrm{rpm}, \mathrm{T}_{i n i}=1500 \mathrm{~K}$ and $\mathrm{P}_{i n i}=1.0 \mathrm{~atm}$.
Table 2. Typical engine geometrical input parameters and initial gas (feed) mixture composition

\begin{tabular}{|l|l|c|c|c|}
\hline $\begin{array}{l}\text { Sr. } \\
\text { No }\end{array}$ & \multicolumn{2}{|c|}{\begin{tabular}{|} 
Engine Geometrical Input \\
Parameters
\end{tabular}} & \multicolumn{2}{c|}{$\begin{array}{c}\text { Initial Gas Mixture (CNG } \\
\text { composition), Mole Fraction }\end{array}$} \\
\hline & Parameter (unit) & Value & \multicolumn{1}{|c|}{ Component } & Mole Fraction \\
\hline 1 & $\begin{array}{l}\text { Cylinder volume } \\
\left(\mathrm{cm}^{3}\right)\end{array}$ & 63 & Methane $\left(\mathrm{CH}_{4}\right)$ & 0.8903 \\
\hline 2 & $\begin{array}{l}\text { Displaced } \\
\text { Volume }\left(\mathrm{cm}^{3}\right)\end{array}$ & 56.52 & Ethane $\left(\mathrm{C}_{2} \mathrm{H}_{6}\right)$ & 0.0105 \\
\hline 3 & $\begin{array}{l}\text { Clearance } \\
\text { Volume }\left(\mathrm{cm}^{3}\right)\end{array}$ & 6.48 & Propane $\left(\mathrm{C}_{3} \mathrm{H}_{8}\right)$ & 0.027 \\
\hline 4 & $\begin{array}{l}\text { Cylinder } \\
\text { Diameters }(\mathrm{cm})\end{array}$ & 14.67 & Butane $\left(\mathrm{C}_{4} \mathrm{H}_{10}\right)$ & 0.0017 \\
\hline 5 & $\begin{array}{l}\text { Crank to } \\
\text { Connecting rod } \\
\text { ratio }\end{array}$ & 1.632 & Nitrogen $\left(\mathrm{N}_{2}\right)$ & 0.072 \\
\hline 6. & $\begin{array}{l}\text { Combustion } \\
\text { Starting Crank } \\
\text { Angle }\end{array}$ & $-142^{\circ}$ & $\begin{array}{l}\text { Carbon Dioxide } \\
\left(\mathrm{CO}_{2}\right)\end{array}$ & 0.026 \\
\hline
\end{tabular}

Table 3. Error analysis of mechanism for output pollutants species concentrations

\begin{tabular}{|l|c|c|}
\hline Pollutant Species & Relative Sum-Square-Root Error & Index of Agreement \\
\hline $\mathrm{CO}$ & $5.17038 \mathrm{E}-08$ & 0.80718 \\
\hline $\mathrm{NO}$ & $7.70665 \mathrm{E}-07$ & 0.92372 \\
\hline $\mathrm{NO}_{2}$ & $1.80863 \mathrm{E}-07$ & 0.95751 \\
\hline $\mathrm{NH}_{3}$ & $1.7466 \mathrm{E}-06$ & 0.79972 \\
\hline
\end{tabular}

\section{Common Simulation Input Parameters}

General inputs of the simulation are:

- Chemical reaction mechanisms with Arrhenius Coefficients,

- Thermodynamic data,

- Molar fractions of reactive species (Natural Gas: $\mathrm{CH}_{4}, \mathrm{C}_{2} \mathrm{H}_{6}, \mathrm{C}_{3} \mathrm{H}_{8}$, and air $-\mathrm{O}_{2}, \mathrm{~N}_{2}$ ) for various equivalence ratios and

- Geometrical parameters of the IC Engine (cylinder displaced volume, clearance volume, crank to connecting rod ratio etc.).

The partial variances $\sigma_{k j}{ }^{2}\left(Y_{i}\right)$ of each individual reaction and their percentage to overall variances illustrate the share of uncertainty of parameter " $j$ " to the uncertainty of output " $i$ ". In this analysis, the reactions which contribute to the uncertainty in output concentrations of pollutant species in each proposed reaction mechanisms are identified.

\section{RESULTS AND DISCUSSION}

The results of variance analysis of kinetic mechanisms is presented and percentage contribution of each reactions involved in the output concentrations of pollutant species is presented. The results of uncertainty analysis of this mechanism are shown in Figure 1 and in Table 3 . The data of approximate models for pollutant species show high accuracy as very low values of Relative Sum-Square-Root Error (RSSRE) and higher values (close to unity) of Index of Agreement (IOA) for each of pollutants under given simulation conditions.

The variance analysis of the formation of pollutants species is shown in Figure 1. The reaction $\mathrm{NO}+\mathrm{C}=\mathrm{CO}+\mathrm{N}$ $(81.8 \%)$ is the main source of uncertainty in the predated concentration of carbon monoxide (CO) under given simulation condition for IC engine. Similarly, the main source of uncertainty in $\mathrm{NO}$ concentrations are reactions $\mathrm{O}_{2}+\mathrm{NCO}=\mathrm{NO}+\mathrm{CO}_{2}(44.4 \%)$ and $\mathrm{O}+\mathrm{HNO}=\mathrm{OH}+\mathrm{NO}$ 

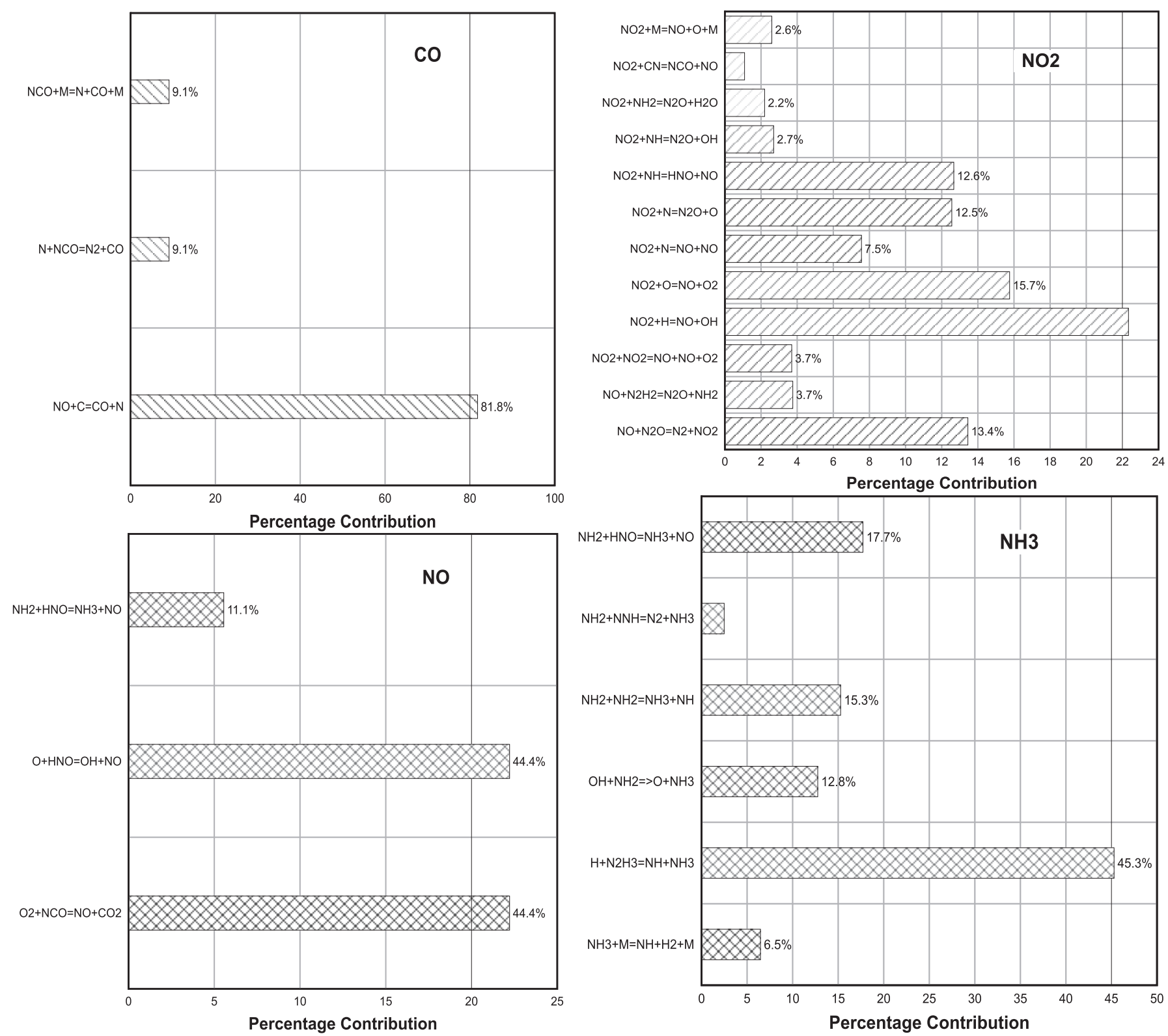

Figure 1. Major reactions contributing to the uncertainty of Pollutant Species $\mathrm{CO}, \mathrm{NO}, \mathrm{NO}_{2}$ and $\mathrm{NH}_{3}$ concentrations at Equivalence ratio $=1.0,3000 \mathrm{rpm}, \mathrm{T}=1500 \mathrm{k}$ and $\mathrm{P}=1.0 \mathrm{~atm}$ for kinetic Model

$(44.4 \%)$ and the following reactions are the major contributor to the uncertainty of nitrogen dioxide $\left(\mathrm{NO}_{2}\right)$; (only reaction with above $10 \%$ )
1. $\mathrm{NO}+\mathrm{N}_{2} \mathrm{O}=\mathrm{N}_{2}+\mathrm{NO}_{2}$
2. $\mathrm{NO}_{2}+\mathrm{H}=\mathrm{NO}+\mathrm{OH}$
3. $\mathrm{NO}_{2}+\mathrm{O}=\mathrm{NO}+\mathrm{O}_{2}$
4. $\mathrm{NO}_{2}+\mathrm{N}=\mathrm{N}_{2} \mathrm{O}+\mathrm{O}$
5. $\mathrm{NO}_{2}+\mathrm{NH}=\mathrm{HNO}+\mathrm{NO}$

Four reactions given below are the main source of uncertainty (above 10\%)
1. $\mathrm{H}+\mathrm{N}_{2} \mathrm{H}_{3}=\mathrm{NH}+\mathrm{NH}_{3}$
2. $\mathrm{OH}+\mathrm{NH}_{2}=>\mathrm{O}+\mathrm{NH}_{3}$
3. $\mathrm{NH}_{2}+\mathrm{NH}_{2}=\mathrm{NH}_{3}+\mathrm{NH}$
4. $\mathrm{NH}_{2}+\mathrm{HNO}=\mathrm{NH}_{3}+\mathrm{NO}$

\section{CONCLUSION}

The variance analysis and error analysis of the proposed kinetic model was carried out. The approximate models showing the contribution of the variation input variables were determined for pollutants $\left(\mathrm{CO}, \mathrm{NO}, \mathrm{NO}_{2}\right.$ $\left.\& \mathrm{NH}_{3}\right)$ species formed in IC engine. The variance analysis identified the reactions which contribute to the uncertainty in the output of the approximate models from the individual reactions involving the formation or consumption of pollutants. The error analysis produced very useful results. The error analysis of approximate models from the proposed kinetic models predicts that this mechanism produces accurate results.

\section{ACKNOWLEDGEMENT}

The authors are thankful to Higher Education Commission for funding this study.

\section{LITERATURE CITED}

1. Rabitz, H., Kramer, M. \& Dacol, D. (1983). Sensitivity analysis in chemical kinetics. Annals of Rev. Phys. Chem. 34, 419-461.

2. Turianyi, T. (1990) Sensitivity analysis of complex kinetic systems: tools and applications. J. Math. Chem. 5, 203-248.

3. Radhakrishnan, K. (1990). Numerical approaches to combustion modelling. In Progress in Astronautics and Aeronautics, vol. 135, pp. 83-128, eds Oran E.S., and Boris J.P. AIAA, Washington.

4. Radhakrishnan, K. (1987). Advances in Computer Methods 
for Partial Differential Equations - VI, eds Vichnevetsky R., Stepleman R. S. IMACS, New Brunswick, NJ,.

5. Tomlin, AS., Turaanyi, T. \& Pilling, M.J. (1997). Mathematical tools for the construction, investigation and reduction of combustion mechanisms. In: Pilling, M.J. (Ed.), Oxidation Kinetics and Autoignition of Hydrocarbons. Elsevier, Amsterdam, pp. 293-437.

6. Battin, F., Leclerc, R., Bounaceur, GM., Côme, R., Fournet, P.A., Glaude, G., Scacchi, \& Warth, V. (2004). EXGAS User's Guide, Department of Chemical Physical Reaction, NANCY, Cedex, France.

7. Mansha, M., Saleemi, A.R., Javed, S.H., \& Nadeem Feroz, (2011). Analysis of a Detailed Kinetic Model of Natural Gas Combustion in IC Engine, Pol. J. Chem. Tech., 13 (1), 6-15. DOI: $10.2478 / \mathrm{v} 10026-011-0002-0$ 